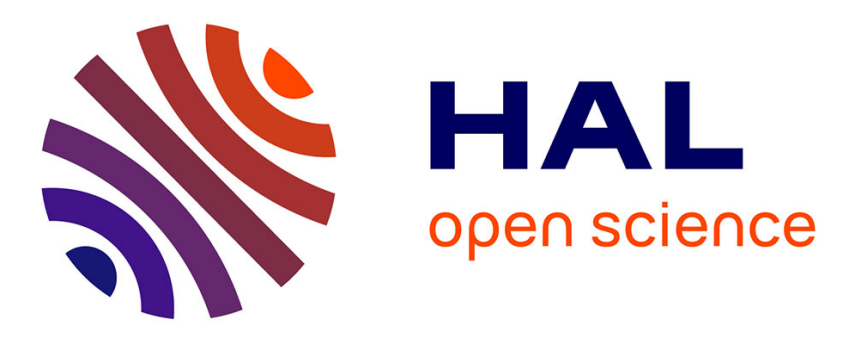

\title{
Unusual activation by solvent of the ethylene free radical polymerization
}

Etienne Grau, Jean-Pierre Broyer, Christophe Boisson, Roger Spitz, Vincent Monteil

\section{- To cite this version:}

Etienne Grau, Jean-Pierre Broyer, Christophe Boisson, Roger Spitz, Vincent Monteil. Unusual activation by solvent of the ethylene free radical polymerization. Polymer Chemistry, 2011, 2 (10), pp.2328-2333. 10.1039/c1py00200g . hal-01874380

\section{HAL Id: hal-01874380 \\ https://hal.science/hal-01874380}

Submitted on 21 Nov 2019

HAL is a multi-disciplinary open access archive for the deposit and dissemination of scientific research documents, whether they are published or not. The documents may come from teaching and research institutions in France or abroad, or from public or private research centers.
L'archive ouverte pluridisciplinaire HAL, est destinée au dépôt et à la diffusion de documents scientifiques de niveau recherche, publiés ou non, émanant des établissements d'enseignement et de recherche français ou étrangers, des laboratoires publics ou privés. 


\title{
Unusual Activation by Solvent of the Ethylene Free Radical Polymerization
}

\author{
Etienne Grau, ${ }^{\text {a }}$ Jean-Pierre Broyer, ${ }^{\text {a }}$ Christophe Boisson, ${ }^{\text {a }}$ Roger Spitz, ${ }^{\text {a }}$ and Vincent Monteil*a \\ Received (in $X X X, X X X) X t h X X X X X X X X X 20 X X$, Accepted Xth $X X X X X X X X X 20 X X$ \\ DOI: 10.1039/b000000x
}

Ethylene polymerization is performed industrially either by radical polymerization under severe conditions $\left(1000-4000\right.$ bar, $200-300^{\circ} \mathrm{C}$ ) or by catalytic mechanism at lower temperatures (usually less than $100^{\circ} \mathrm{C}$ ) and pressures (below 50 bar). Standard radical polymerization conditions are too severe to permit a fine control of the macromolecular architecture. Under milder conditions $\left(100 \mathrm{bar}, 70^{\circ} \mathrm{C}\right)$, radical ethylene polymerization is assumed ineffective which has been confirmed in bulk (supercritical ethylene). However, we have shown that the efficiency of this polymerization is strongly dependant of the solvent. This unusual activation by solvent has been rationalized using theoretical considerations. A second effect investigated is the influence of solvent on PE molecular weight. Indeed PE with either low molecular weight and high chain-end functionality or higher molecular weight can be synthesized according to the solvent used.

\section{Introduction}

Polyethylene is one of the most important polymers in the everyday life. Although it has been seven decades since polyethylene's first commercialization, polyolefins remain highly technology driven. The three major classes of polyethylene are described by acronyms HDPE, LDPE, and LLDPE. High-density polyethylene (HDPE) is a linear, semi-crystalline ethylene homopolymer prepared by Phillips or Ziegler-Natta polymerization process. ${ }^{[1,2]}$ Linear low-density polyethylene (LLDPE) is a random copolymer of ethylene and $\alpha$-olefins produced commercially using Phillips, Ziegler-Natta, and metallocene catalysts. These catalytic processes were developed generally under mild experimental conditions $\left(\mathrm{T}<100^{\circ} \mathrm{C}\right.$ and $\mathrm{P}<100$ bar). Low-density polyethylene (LDPE) is a branched homopolymer prepared under high-temperature and high-pressure via a free radical polymerization process. ${ }^{[3,4]}$

Free radical polymerization of ethylene is industrially conducted under high pressures (1000-4000 bar) and high temperatures $\left(200-300^{\circ} \mathrm{C}\right)$ in bulk. LDPE melts between 100$120^{\circ} \mathrm{C}$ and exhibits a crystallinity in the range of $30-60 \%$. We have investigated the efficiency of this reaction under milder slurry conditions: pressure up to 250 bar, $\mathrm{T}=70^{\circ} \mathrm{C}^{[5,6]}$ These conditions are less efficient than the industrial process but easier to handle. The PE produced possess higher crystallinities $(\sim 70 \%)$ than the traditional industrial LDPE but molecular weights remain too low for applications $(\mathrm{Mn}<5000 \mathrm{~g} / \mathrm{mol})$. Moreover the influence of the solvent appears to be crucial for the free radical ethylene polymerization. For instance we managed to synthesize polyethylene down to 10 bar in a polar solvent (THF) by a free radical process with activity 6 times higher than in a nonpolar solvent (toluene). ${ }^{[5]}$ This unusual activation by solvent will be further studied in the present work. Indeed free radical polymerization of ethylene will be investigated in a wide range of solvents in order to improve the medium pressure process.

The influence of solvent on free radical polymerization of vinyl compounds was previously reported by Kamachi. ${ }^{[7]}$ For almost all monomers it is a tiny effect except for vinyl acetate ${ }^{[8]}$ and ethylene. ${ }^{[9-12]}$ For these two monomers the kinetics of radical polymerization could vary by a factor up to 10 depending on the solvent. The early studies for ethylene remain partial due to the experimental facilities available at this time (before 1980s). Machi $^{[13]}$ suggested that the solubility of the growing polyethylene chain could induce the activation effect by solvent through a Trommsdorff-Norrish effect but his interpretation is still controversial. ${ }^{[14]}$ Myshkin $^{[9]}$ assumed it was a fully different mechanism based on the dielectric constant $\varepsilon$ of the solvent. For other monomers several explanations for this influence have been proposed but none of them is consistent with all sets of data. The diverse influences of solvent on the free radical polymerization are due to variations of kinetic constants according to solvent parameters. The termination rate ${ }^{[15-17]}$ was partially related to the viscosity of the solvent due to diffusion mechanisms. For the propagation rate, ${ }^{[7,18,19]}$ different origins have been proposed as polarity, interactions between polymer and solvent, interactions between monomer and solvent, and complexation between the propagating macroradical and the solvent. Others authors ${ }^{[20-22]}$ suggested that local monomer concentration could play a major role. In the present paper, we performed the radical polymerization of ethylene in a wide range of solvents and studied their influences on yield of polymerization and molecular weight of produced polyethylene. Thanks to theoretical studies, we suggest a new relation which links the yield of polymerization to a combination of key solvent parameters. 
Table 1 Solvent effect on free radical polymerization of ethylene $\mathrm{e}^{\mathrm{a}]}$

\begin{tabular}{|c|c|c|c|c|c|c|c|}
\hline $\operatorname{Run}^{[\mathrm{a}]}$ & Solvent & $\begin{array}{l}\varepsilon \text { : Dielectric constant } \\
\quad\left(\text { at } 20^{\circ} \mathrm{C}\right)^{[\mathrm{b}]}\end{array}$ & $\begin{array}{l}\mu \text { : Dipole momentum } \\
\quad\left(10^{-30} \text { C.m }\right)^{[\mathrm{b}]}\end{array}$ & Yield (g) & $\begin{array}{l}\text { Melting point }\left({ }^{\circ} \mathrm{C}\right)^{\mathrm{c}} \\
{[\text { Crystallinity }(\%)]}\end{array}$ & $\operatorname{Mn}(\mathrm{g} / \mathrm{mol})^{\mathrm{d}}$ & $\mathrm{PDI}^{\mathrm{d}}$ \\
\hline 1 & supercritical ethylene & - & 0 & 0.1 & $105.3[46]$ & 3010 & 1.3 \\
\hline 2 & Cyclohexane & 2.0 & 0 & 0.6 & $115.5[58]$ & 4800 & 2.2 \\
\hline 3 & Heptane & 1.9 & 0 & 0.65 & $116.7[55]$ & 4700 & 2.1 \\
\hline 4 & Toluene & 2.4 & 1 & 0.7 & $115.9[63]$ & 2340 & 1.9 \\
\hline 5 & Dimethyl sulfoxide & 46.4 & 13.5 & 1 & $112.7[43]$ & 1910 & 3.5 \\
\hline 6 & Acetonitrile & 35.9 & 11.8 & 1.1 & $115.5[59]$ & 1370 & 2.2 \\
\hline 7 & Diethylcarbonate & 2.8 & 3.7 & 1.2 & $117.8[62]$ & 7150 & 2.5 \\
\hline 8 & N,N-Dimethyl-formamide & 36.7 & 10.8 & 1.3 & $108.5[47]$ & 530 & 2.9 \\
\hline 9 & Dibutylether & 3.1 & 3.9 & 1.3 & $109.0[52]$ & 1370 & 1.4 \\
\hline 10 & Ethanol & 24.5 & 5.8 & 1.4 & $117.6[63]$ & 2130 & 2.4 \\
\hline 11 & Acetone & 20.6 & 9 & 1.5 & $115.2[62]$ & 1710 & 2.0 \\
\hline 12 & Dimethylcarbonate & 3.2 & 3.7 & 1.6 & $117.9[57]$ & 11720 & 2.5 \\
\hline 13 & Butanone & 18.5 & 9.2 & 1.8 & 61 [nd] & 370 & 1.2 \\
\hline 14 & Butyrolactone & 39.0 & 14.2 & 1.8 & nd [nd] & 570 & 1.4 \\
\hline 15 & Butan-2-ol & 16.6 & 5.5 & 1.9 & $116.4[68]$ & 2070 & 2.8 \\
\hline 16 & Cyclohexanone & 16.0 & 10.2 & 2.1 & nd [nd] & 1760 & 1.5 \\
\hline 17 & Butan-1-ol & 17.5 & 5.8 & 2.2 & $117.8[58]$ & 4130 & 2.4 \\
\hline 18 & Ethyl acetate & 6.0 & 6.1 & 2.3 & $115.2[54]$ & 3760 & 3.3 \\
\hline 19 & Dichloromethane & 8.9 & 5.2 & 2.7 & $105.1[46]$ & 1050 & 1.6 \\
\hline 20 & 1,4-dioxane & 2.2 & 1.5 & 3.2 & $118.9[65]$ & 1300 & 2.2 \\
\hline 21 & Tetrahydrofurane & 7.6 & 5.8 & 3.9 & $115.2[58]$ & 1190 & 1.9 \\
\hline
\end{tabular}

${ }^{a}$ The reactions were carried using $50 \mathrm{mg}$ of AIBN in $50 \mathrm{~mL}$ of purified solvent at $70^{\circ} \mathrm{C}$ under 100 bar of ethylene pressure during 4 hours. ${ }^{b}$ obtained from reference $24{ }^{\mathrm{c}}{ }^{\mathrm{C}}$ determined by DSC, ${ }^{\mathrm{d}}$ dertermined by HTSEC, nd= not determined

\section{Experimental Section}

All chemicals were purified using standard Schlenk procedures and handled under argon atmosphere. Solvents were distilled from drying agents and degassed under argon. Ethylene (purity 99.95\%) was purchased from Air Liquide and AIBN from Acros and used without any further purification.

\section{Polymer characterizations}

Molecular weights of polyethylenes were determined by size exclusion chromatography (SEC) using a Waters Alliance GPCV 2000 instrument (columns: PLgel Olexis); two detectors (viscosimeter and refractometer) in trichlorobenzene (flow rate: 1 $\mathrm{mL} / \mathrm{min}$ ) at $150^{\circ} \mathrm{C}$. The system was calibrated with polystyrene standards using universal calibration. Differential scanning calorimetry (DSC) was performed on a Mettler Toledo DSC1 at a heating rate of $5 \mathrm{~K} / \mathrm{min}$. Two successive heating and cooling steps of the samples were performed. We have considered data (Tm values, crystallinity) obtained during the second heats.

\section{Standard polymerization procedure of ethylene}

Caution, all polymerizations involve high pressure and explosive gas.

Ethylene polymerizations were done in a $160 \mathrm{~mL}$ stainless steel autoclave (equipped with safety valves, stirrer, oven) from Parr Instrument Co.. The azobisisobutyronitrile (AIBN) was dissolved in $50 \mathrm{~mL}$ of desired solvent in a Schlenk tube under argon. The mixture was introduced through cannula into the reactor. Ethylene was introduced and the mixture was heated at the desired temperature under stirring (300 rpm). To manage safely polymerization over 50 bar of ethylene we use a $1.5 \mathrm{~L}$ intermediate tank. The tank was cooled down to $-20^{\circ} \mathrm{C}$ to liquefy ethylene at 35 bar. When thermodynamic equilibrium was reached, the intermediate tank was isolated and heated to reach up to 300 bar of ethylene pressure. This tank was used to charge the reactor, and maintain pressure of ethylene constant in the reactor by successive manual ethylene addition. After 4 hours of polymerization the reactor was slowly cooled down and degassed. The precipitated polymer was then dried under vacuum at $70^{\circ} \mathrm{C}$.

\section{Results and discussion}

Ethylene free radical polymerization in various organic solvents

Free radical polymerizations of ethylene under identical conditions $\left(100 \mathrm{bar}, 70^{\circ} \mathrm{C}, 50 \mathrm{~mL}\right.$ of solvent) were performed in a wide range of solvents. Polymerizations results are presented in Table 1. As it can be seen from Table 1, polymerization yield is highly dependent on the solvent of polymerization (from $0.1 \mathrm{~g}$ to $4 \mathrm{~g}$ ). If we consider that solubility of ethylene is almost the same for all solvents $\left(470 \mathrm{~g} / \mathrm{L} \text { under } 100 \text { bar at } 70^{\circ} \mathrm{C}\right)^{[23]}$ then conversions in presence of solvent are between $3 \%$ and $17 \%$.

In pure ethylene, without any solvent, the polymerization of ethylene is almost inefficient (run $1,0.1 \mathrm{~g}$ corresponding to a conversion of $0.3 \%$ ). The resulting polyethylene synthesized exhibits a low melting point, $105^{\circ} \mathrm{C}$, and consequently appears close to LDPE with low molecular weight $(3000 \mathrm{~g} / \mathrm{mol})$. In all cases, a higher activity is measured in the presence of solvent. Therefore solvents seem to play a major role in the activation of the radical polymerization of ethylene. However, all solvents did not lead to the same activation (yield ranges from $0.6 \mathrm{~g}$ in cyclohexane to $3.9 \mathrm{~g}$ in $\mathrm{THF}$ ) and in first approximation, it 
appears that non polar solvents are less efficient than polar ones.

\section{Effect of solvent on the PE molecular weights}

PE molecular weights are strongly related to the solvent (see Table 1) due to transfer reaction to solvent. The highest molecular weights are reached in dimethylcarbonate $(\mathrm{Mn}=11700$ $\mathrm{g} / \mathrm{mol}$ - run 12), and the lowest in butanone $(\mathrm{Mn}=370 \mathrm{~g} / \mathrm{mol}$ - run 13). The transfer ability of the solvent can be related to the calculated number of chains per initiator. ${ }^{[25]}$ Cyclohexane $(\mathrm{Mn}=4800 \mathrm{~g} / \mathrm{mol}$ - run 2) is the less transferring solvent, while butanone is found to be the highest. Toluene (run 4) is the non polar solvent with the highest transfer ability, 2.4 times more than cyclohexane. Finally dimethylcarbonate is the less transferring polar solvent (only 1.1 times more than cyclohexane) and consequently lead to the highest molecular weights.

Solvent with high transfer ability can be used to obtain a high content of PE chain-end functionality. One of the most transferring solvent is THF, 26 times higher than cyclohexane. Transfer to solvent provided THF-ended polyethylenes which were fully identified by ${ }^{13} \mathrm{C}$ NMR (see ESI, Fig. S1). ${ }^{[5]}$ The ${ }^{13} \mathrm{C}$ NMR spectrum exhibits standard chemical shift ${ }^{[26]}$ of a branched polyethylene (9 branches/1000C). Additionaly two different structures, 1- and 2-polyethylenyl-THF, were identified. The chain-end functionalized PE obtained from transfer to solvent may be used further as macro-monomers. Chain-end labelling from transfer to solvent were also determined by ${ }^{13} \mathrm{C}$ NMR for other solvents such as toluene, dioxane (run 20), dichloromethane (run 19, see ESI, Fig. S2, S3, S4).

An interesting solvent for further use of chain-end functionalized PE is butyrolactone (run 14). The resulting macromonomer could be used in copolymerization with lactones via ring-opening polymerization in order to obtain polyester with PE branches. Otherwise, chloro-terminated PE from transfer to dichloromethane could also be used as starting reactant for nucleophilic substitution.

On the other hand, solvents with low transfer ability and high activity will provide non functional polyethylenes. Usually, high transfer ability is related to high activities, except for ethyl acetate (run 18) which is a particularly poor transferring solvent (but still 4.9 times more transferring than cyclohexane), for butan-1-ol (run 17), and for carbonates (runs 7 and 12). These solvents provide PE with relatively higher molecular weights (over $10000 \mathrm{~g} / \mathrm{mol}$ ).

Consequently, free radical polymerization of ethylene in solvent can provide either, functional/low-molecular weight polyethylenes or non-functional/higher-molecular weight polyethylenes.

\section{Rationalization of the activation by solvent during ethylene radical polymerization}

We have evidenced a strong solvent influence on yield in the free radical polymerization of ethylene. This high solvent effect could not be related directly to solvent parameters such as solvent viscosity, dipole momentum, dielectric constant or solubility parameters. THF activates the polymerization 2.8 times more than ethanol (run 12) despite similar dipole momenta. Toluene is 4.6 times less efficient than 1,4-dioxane while they possess the same dielectric constants. No simple relations between the yield and solvent properties such as dielectric constant $(\varepsilon)$ or dipole momentum $(\mu)$ or other physical constants seemed to exist.

To quantify the solvent effect we used the theory of the activated complex $^{[27]}$ (equation 1) which links a kinetic constant in a solvent to a kinetic constant without solvent. In this theory, the solvent effect is due to the preferential interactions between the solvent and the activated complex or the reactants. In the case of the free radical polymerization of ethylene, this stabilization is only due to Van der Waals interactions, that is, Keesom (dipoledipole), Debye (dipole-induced dipole) and London (instantaneous dipole-induced dipole) interactions ${ }^{[28]}$ (equations 2-4). Keesom interactions are assumed to be the principal interactions which stabilize the macroradical $\left(E_{\text {Keesom }}>E_{\text {Debye }}\right.$ and ELondon). Consequently, each kinetic constant of the polymerization $\left(\mathrm{k}_{\mathrm{d}}, \mathrm{k}_{\mathrm{p}}, \mathrm{k}_{\mathrm{t}}\right.$ or $\mathrm{k}_{\mathrm{tot}}$ ) exhibits a relation (equation 5) with different solvent properties $(\varepsilon, \mu)$. Thus, according to the free radical kinetic law (equation 6 ), $\mathrm{k}_{\mathrm{tot}}$ and therefore yield can be related to $(\mu / \varepsilon)^{2}$ (equation 7 ). Since only $k_{\text {tot }}$ is accesible in this experiment we can not determined the relative dependancy of $\mathrm{k}_{\mathrm{p}}$, $\mathrm{k}_{\mathrm{t}}, \mathrm{k}_{\mathrm{d}}$ with $(\mu / \varepsilon)^{2}$. However it is expected that $\mathrm{k}_{\mathrm{t}}$ will have a little dependancy since it is mostly controlled by diffusion processes $^{[16,17]}$.

It should be noted that the transfer to solvent usually does not impact the kinetic of the poylmerization. Indeed the transfer reaction does not modify the radical concentration (Steady States Approximation). However in specific cases the resulting radical cannot efficiently react with monomer and consequently slows down the polymerization. It appears not to be the case for ethylene polymerization as for example THF and dibutylether lead to similar radical $\left(\mathrm{O}-\mathrm{CH}^{\bullet}-\mathrm{CH}_{2}\right)$ but different activity (run 9 and 21).

$$
\begin{aligned}
& \ln k=\ln k_{0}-\frac{1}{R T}\left(\Delta G_{R, \text { solv }}+\Delta G_{M, \text { solv }}-\Delta G_{(R M)^{*}, \text { solv }}\right) \\
& E_{\text {Keesom }}=-\frac{1}{3 r^{6}}\left[\frac{\mu_{\text {solvent }}^{2} \cdot \mu_{\text {radical }}^{2}}{\left(4 \pi \cdot \varepsilon_{0} \cdot \varepsilon_{\text {solvent }}\right)^{2} k_{B} T}\right] \\
& E_{\text {Debye }}=-\frac{1}{r^{6}}\left[\frac{\mu_{\text {solvent }}^{2} \cdot \alpha_{\text {radical }}+\mu_{\text {radical }}^{2} \cdot \alpha_{\text {solvent }}}{\left(4 \pi \cdot \varepsilon_{0} \cdot \varepsilon_{\text {solvent }}\right)^{2}}\right] \\
& E_{\text {London }}=-\frac{1}{r^{6}}\left[\frac{3}{4} \cdot \frac{h \cdot v \cdot \alpha_{\text {solvent }} \cdot \alpha_{\text {radical }}}{\left(4 \pi \cdot \varepsilon_{0}\right)^{2}}\right] \\
& \ln k \propto\left(\frac{\mu}{\varepsilon}\right)^{2} \\
& \frac{1}{1-x} \frac{\partial x}{\partial t}=k_{p} \sqrt{\frac{2 f k_{d}[I]}{k_{t}}}=\mathrm{k}_{\text {tot }} \\
& \ln \ln \frac{1}{1-x} \propto\left(\frac{\mu}{\varepsilon}\right)^{2}
\end{aligned}
$$

Where $k$ is any kinetic constant in the solvent, $k_{0}$ the constant without solvent, $R$ the ideal gas constant, $T$ the absolute temperature, $\Delta G$ the solvation Gibbs energy of the initial (macroradical, $\mathrm{R}$, and monomer, $\mathrm{M}$ ) and activated state $\left(\mathrm{RM}^{\ddagger}\right), r$ the distance between the molecules, $\mu$ the dipole momentum, $\alpha$ the polarizability, $\varepsilon_{0}$ the permittivity of the vacuum, $\varepsilon$ the dielectric constant, $h$ the Planck constant, $v$ the absorbing electromagnetic radiation frequency, $x$ the conversion of the polymerization assuming a free radical kinetic law, [I] the AIBN concentration, $f$ the efficiency factor of the initiator and with the 
kinetic constants of initiator dissociation $\left(k_{d}\right)$, propagation $\left(k_{p}\right)$ and termination $\left(k_{t}\right)$ and global constant ktot.

We plotted the conversion versus $(\mu / \varepsilon)^{2}$ (Fig. 1), in order to confirm this relation.

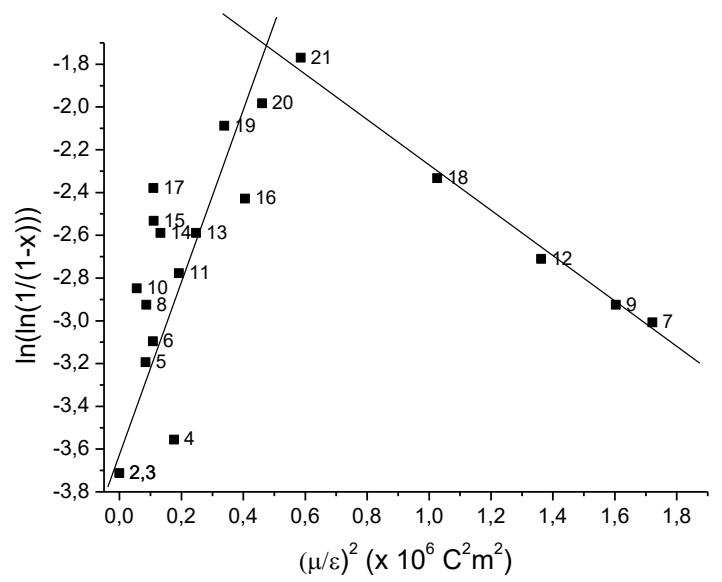

Fig. 1 Solvent influence due to Keesom interactions on radical polymerization of ethylene (labels correspond to run numbers in Table 1). 口 : $50 \mathrm{mg}$ AIBN, $50 \mathrm{~mL}$ of solvent $4 \mathrm{~h}$ at $70^{\circ} \mathrm{C}$ under 100 bar of ethylene pressure.

The curve obtained is unexpectedly $\Lambda$-shaped. A change of behavior is observed for Keesom interactions higher than the ones for THF $\left((\mu / \varepsilon)^{2}{ }_{\text {optimum }} \approx 0.5810^{-60} \mathrm{C}^{2} \cdot \mathrm{m}^{2}\right)$. At lower value of $(\mu / \varepsilon)^{2}$, yield increases with this parameter, while it decreases over this value. Most of the solvents showed a good correlation between polymerization yield and $(\mu / \varepsilon)^{2}$.

For alcohols (runs 10,15,17) such as ethanol an "over yield" is observed. This can be due to H-bond interactions which have been neglected in the theory. Indeed stabilization by solvent can take place not only by Van der Waals interactions but also by $\mathrm{H}$ bond interactions in this case.

\section{Case of solvent mixtures}

In order to validate the interpretation of this solvent effect we performed polymerizations using different binary and ternary mixtures of toluene, THF, and diethylcarbonate (DEC) as solvent (Fig. 2). By this way, we artificially change the $(\mu / \varepsilon)^{2}$ of the solvent by mixing solvents.

Standard mixing rules ${ }^{[29]}$ respectively for relative permittivity $\varepsilon$ mixture $=\Sigma x_{\mathrm{i}} \varepsilon_{\mathrm{i}}$, with $x_{\mathrm{i}}$ the volume fraction of solvent $i$ and $\varepsilon_{\mathrm{i}}$ the solvent $i$ relative permittivity and for dipole $\mu_{\text {mixture }}=\Sigma \Sigma x_{\mathrm{i}} x_{\mathrm{j}}\left(\mu_{\mathrm{i}} \mu_{\mathrm{j}}\right)^{1 / 2}$, with $\mu_{\mathrm{i}}$ the dipole momentum of the solvent $i$ are used.

In all cases, whatever the mixture composition, the $\Lambda$-shaped curve is observed once again between conversion and values of $(\mu / \varepsilon)^{2}$. The maximum of activity (yield $4.1 \mathrm{~g}$ ) was reached for $(\mu / \varepsilon)^{2}{ }_{\text {optimum }} \approx 0.6510^{-60} \mathrm{C}^{2} . \mathrm{m}^{2}$. Polymerizations in Toluene-DEC mixture follow the same curve than toluene-THF and THF-DEC mixtures. So by tuning properly the proportion of toluene-DEC mixture we are able to provide the same activity than the ethylene polymerization in THF. This evidences that the solvent interaction with the alkyl radical is an exact average of the solvent composition and is not due to nature of the solvent itself. In other words the solvation shell of the alkyl radical presents the same composition than the solvent composition, there are not preferred interactions with one of the solvents.

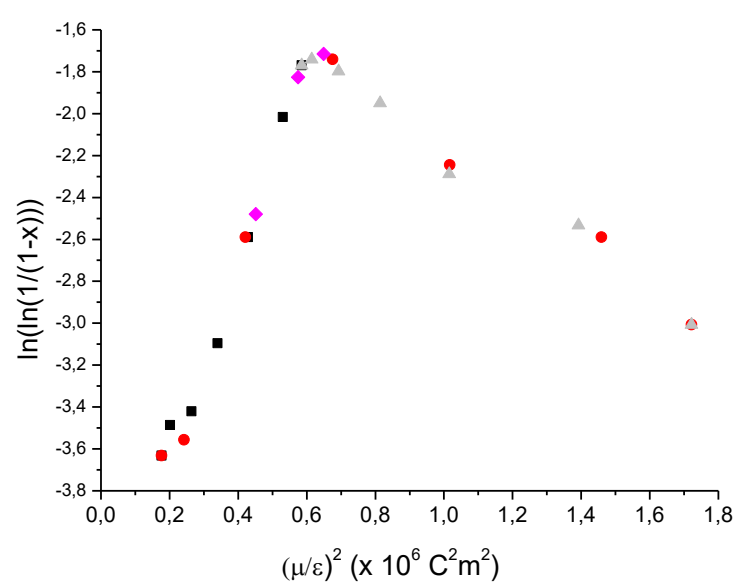

Fig. 2 Solvent mixture composition influence related to Keesom interactions on radical polymerization of ethylene.

$50 \mathrm{mg}$ AIBN $4 \mathrm{~h}$ at $70^{\circ} \mathrm{C}$ under 100 bar of ethylene pressure in $50 \mathrm{~mL}$ of : THF-toluene; $\triangle: T H F-D E C$; $\bigcirc$ toluene-DEC; : THF-toluene-DEC mixture

Using solvent mixtures, conversion higher than in THF can be reached. Moreover the activation by the solvent appears to be uncoupled from the control of molecular weight by transfer to solvent as evidenced by the molecular weights of synthesized polyethylenes (see ESI, Table S1). For example, a Toluene/DEC $50 / 50 \mathrm{v} / \mathrm{v}$ mixture provides about the same polymerization activity as THF but does not lead to the same molecular weight: respectively $3200 \mathrm{~g} / \mathrm{mol}$ and $1200 \mathrm{~g} / \mathrm{mol}$. Therefore as the solvent activation effect is a global solvent effect only related to $\mu$ and $\varepsilon$, and molecular weight mostly controlled by the nature of the solvent (or solvent mixture) used, yield and average molecular weight can be tuned easily by choosing a suitable mixture of solvents.

\section{Arrhenius parameters of free radical polymerization of ethylene in various solvents}

To go further we calculated the global activation energy and global pre-exponential factor of the ethylene free radical polymerization. For this purpose, we performed polymerizations at various temperatures $\left(50^{\circ} \mathrm{C}, 70^{\circ} \mathrm{C}\right.$ and $\left.90^{\circ} \mathrm{C}\right)$ and ethylene pressures (from 50 bar to 250 bar) in all three solvents used previously in mixture. One can remark that ethylene conversion seemed not to be linked to ethylene pressure (see ESI table S3). From these experiments, we plotted ln ktot (global kinetic constant of the radical polymerization - see equation $8 \mathrm{a}, 8 \mathrm{~b}$ ) versus $1 / \mathrm{T}$ to determine Arrhenius parameters. Corresponding $\mathrm{E}_{\text {tot }}$ and $\ln \left(\mathrm{A}_{\mathrm{tot}}\right)$ are summarized in Table 2 . 
Table 2 Arrhenius parameters of ethylene polymerization ${ }^{\mathrm{a}}$

\begin{tabular}{cccc} 
Solvent & $\begin{array}{c}(\mu / \varepsilon)^{2}: \\
\left(10^{-60} \mathrm{C}^{2} \cdot \mathrm{m}^{2}\right)^{1}\end{array}$ & $\begin{array}{c}\mathrm{E}_{\text {tot }}-\text { Global } \\
\text { activation energy } \\
(\mathrm{kJ} / \mathrm{mol})^{\mathrm{b}}\end{array}$ & $\begin{array}{c}\ln \left(\mathrm{A}_{\text {tot }}\right)-\text { Global } \\
\text { preexponential } \\
\text { factor }^{\mathrm{b}}\end{array}$ \\
\hline Toluene & 0.18 & 27.7 & 7.6 \\
THF & 0.58 & 32.8 & 10.3 \\
DEC & 1.72 & 40.0 & 12.2 \\
\hline
\end{tabular}

${ }^{a}$ assuming the validity of Arrhenius law.

Ideally, the determination of the Arrhenius parameters for each polymerization step should be performed, but this kind of study is currently incompatible with our experimental conditions of pressure (stopped flow or pulsed laser polymerizations techniques cannot be easily used).

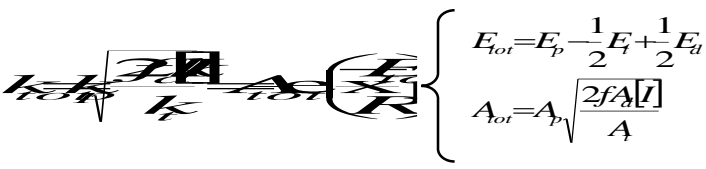

Both global activation energy and pre-exponential factor increase with $(\mu / \varepsilon)^{2}$. On one hand, lower global activation energy is usually linked to a more favorable reaction. In all solvents, the polymerization mechanism is considered to be the same, so the change in the global activation energy is only due to the relative stabilization of intermediate and activated states, which differ from one solvent to the other. ${ }^{[30]}$ Solvation by toluene provides a lower energy barrier than in THF and DEC. On the other hand, the global pre-exponential factor is proportional to the frequency of efficient collisions. With a higher pre-exponential factor the probability of the mechanism involved is supposed to increase. Differences in geometry of activated states ${ }^{[26]}$ in toluene, in THF and in DEC could explain the difference of pre-exponential factors. Toluene is less electron donor than THF, more toluene molecules are necessary to stabilize the radical. Thus the radical should have a denser solvation shell in toluene than in THF. This could explain why preexponential factor is higher in THF than in Toluene. The same reasonement could be applied for DEC. For these three solvents, a linear relationship seem to exist between $\mathrm{E}_{\text {tot }}$ and $(\mu / \varepsilon)^{2}$, in the same way $\ln \left(\mathrm{A}_{\mathrm{tot}}\right) \mathrm{vs}(\varepsilon / \mu)^{2}$ is linear. These two relations allow to calculate the Arrhenius parameters for every $(\mu / \varepsilon)^{2}$ and to predict the optimum of solvent activation. The optimum depends of the temperature (in Kelvin the relation is $\left.(\mu / \varepsilon)^{2}{ }_{\text {optimum }} \approx 0.03 \quad \mathrm{~T}^{1 / 2} 10^{-60} \mathrm{C}^{2} \cdot \mathrm{m}^{2}\right) .^{[31]}$ Therefore at $70^{\circ} \mathrm{C}$ the predict optimum is $(\mu / \varepsilon)^{2}$ optimum $\approx 0.5610^{-60} \mathrm{C}^{2} \cdot \mathrm{m}^{2}$.

\section{Interpretation of the solvent optimum}

The optimum of solvent properties was calculated by three different techniques $(\mu / \varepsilon)^{2}$ optimum $\approx 0.56-0.6510^{-60} \mathrm{C}^{2} \cdot \mathrm{m}^{2}$ at $70^{\circ} \mathrm{C}$ (different solvents, mixture of solvents and Arrhenius parameters). This optimum solvent property is close to the $(\mu / \varepsilon)^{2} \approx 0.6210^{-60} \mathrm{C}^{2} . \mathrm{m}^{2}$ of an alkyl macroradical $\left(\mu \approx 1.510^{-30} \mathrm{C} . \mathrm{m}\right.$ and $\varepsilon \approx 1.9$ ). The punctual dipole momentum of an alkyl macroradical has been determined on the basis of a 1-hexyl radical. It has been determined by GAUSSIAN03 ${ }^{[32]}$ calculation (see ESI, Figure S5 and Table S3) of partial charge and geometry of the radical $\mu_{\text {radical }}=\Sigma q_{i} r_{i}$ with $q_{i}$ the partial charge of the $i$ atom, and $r_{i}$ a vector from some reference to the atom $i$. The relative permittivity $\varepsilon$ corresponds to the permittivity of the growing chain-end, and therefore it could be approximated to a molecule similar to the saturated chain end (for macroradical of the free radical polymerization of ethylene we have chosen heptane). Consequently optimal solvent is reached when its $(\mu / \varepsilon)^{2}$ is the closest to the $(\mu / \varepsilon)^{2}$ of the propagating radical.

\section{Possible interpretation of the activation of ethylene free radical polymerization by solvent}

The solvent activation effect on the free radical polymerization of ethylene is correlated to Keesom interactions between the radical and the solvent. This interaction is not punctual but is due to the average composition of the solvation shell of the macroradical. The decrease of the Keesom interaction lowers the global activation energy (due to a decrease of the stabilization), as the global pre-exponential factor (due to a thickening of the macroradical's solvation shell). The intensity of the solvent effect remains an open question. This optimum $(\mu / \varepsilon)^{2}$ is close to the corresponding same parameters of the macroradical $(\mu / \varepsilon)^{2}$.

Otherwise the optimum corresponds to the radical stemming from monomer, not to the radical fragment issued from AIBN. Therefore the initiation (first addition of the monomer) is not the determining step in the solvent activation effect. Indeed if it was the case the optimum $(\mu / \varepsilon)^{2}$ would correspond to the $(\mu / \varepsilon)^{2} \approx 0.02$ $10^{-60} \mathrm{C}^{2} \cdot \mathrm{m}^{2}$ of the radical resulting from AIBN dissociation $\left(\mu \approx 1.610^{-30}\right.$ C.m and $\varepsilon \approx 25$ - see ESI, Figure S6 and Table S4). Consequently it must be the propagation and/or termination steps which are influenced by the solvent.

It should be noted that for standard monomers (MMA, Sty, $\mathrm{BuA})$, the solvent effect remains tiny. ${ }^{[7,10]}$ These monomers possess higher propagation rate and lower termination rate than the monomers (ethylene, vinyl acetate) which exhibit a solvent activation effect. So only monomers, which possess low propagation rate or high termination rate, seem to express a high solvent effect.

\section{Conclusion}

In conclusion, we have reported the radical polymerization of ethylene under mild conditions $\left(\mathrm{P}=100 \mathrm{bar}, \mathrm{T}=70^{\circ} \mathrm{C}\right)$ in a wide range of solvents. Important activation by solvent has been observed.

Moreover, the crucial importance of solvent transfer capacities on the nature of synthesized PE was evidenced. Indeed since the alkyl radical possesses a high reactivity, the transfer constants to solvents are high and the molecular weight of the PE synthesized is controlled by transfer to solvent. This transfer to solvent can be used to functionalize PE chain-end Carbonates are the less transferring solvents and $\mathrm{Mn}$ values up to $15000 \mathrm{~g} / \mathrm{mol}$ are reached. This molecular weight far over the entanglement molecular weight should lead to some attractive mecanical properties. Activation by solvent and molecular weight control be transfer appears to be unlinked.

We observe that the major factor to explain the solvent activation effect is the Keesom interaction of the solvent on the macroradical and therefore demonstrated a good correlation between yield of polymerization and solvent properties $\left((\mu / \varepsilon)^{2}\right)$. This $\Lambda$-shaped relation demonstrates that a optimal solvent exists for ethylene radical polymerization and possess a $(\mu / \varepsilon)^{2}$ close to $0.610^{-60} \mathrm{C}^{2} \cdot \mathrm{m}^{2}$. The same optimum has been identified using two other techniques: solvent mixtures and Arrhenius parameters. 
Moreover, this optimum is correlated to the corresponding $(\mu / \varepsilon)^{2}$ of the propagating radical. Finally, we have demonstrated that this solvent activation effect is not a punctual effect of the solvent but a global average effect of the solvation shell of the growing radical and is only dependent of the average $\mu$ and $\varepsilon$ of the solvent mixture.

\section{Acknowledgements}

E.G. thanks the "Ministère de la Recherche et de l'Enseignement Supérieur" for fellowship. The authors thank Mettler-Toledo for the thermal analysis.

\section{Notes and references}

${ }^{a}$ Université de Lyon, Univ. Lyon 1, CPE Lyon, CNRS, UMR 5265 Laboratoire de
Chimie Catalyse Polymères et Procédés (C2P2), LCPP team
Bat 308F, 43 Bd du 11 novembre 1918, F-69616 Villeurbanne, France.
Fax: (+33) 4724317 68; E-mail: monteil@lcpp.cpe.fr
$\dagger$ Electronic Supplementary Information (ESI) available: Text detailling
calculations; NMR spectra of PE synthesized in THF, toluene, dioxane
and dichloromethane; Tables showing the influence of the mixture
composition and the temperature on the free radical polymerization of
ethylene, and GAUSSIAN03 output for 1-hexyl radical and AIBN radical
fragment. See DOI: 10.1039/b000000x/

1 R. Mulhaupt, Macromol. Chem. Phys., 2003, 204, 289.

2 D.L. Beach and Y.V. Kissin, in Encyclopedia of Polymer Science and Engineering, 2nd ed., Vol. 6 (Eds: H.F. Mark, N.M. Bikales, C.G. Overberger and G. Menges), WileyInterscience: New York, 1985, pp 454-489.

3 K.W. Doak, in Encyclopedia of Polymer Science and Engineering, 2nd ed., Vol. 6 (Eds: H.F. Mark, N.M. Bikales, C.G. Overberger and G. Menges), WileyInterscience: New York, 1985, pp 386-428.

4 S.L. Aggarwal, O.J. Sweeting, Chem. Rev., 1957, 57, 665.

5 E. Grau, J.P. Broyer, C. Boisson, R. Spitz and V. Monteil, Macromolecules, 2009, 42, 7279.

6 Grau, E., Broyer, J.P., Boisson, C., Spitz, R. and Monteil, V. Phys. Chem. Chem. Phys., 2010, 12, 11665.

7 M. Kamachi, Adv. Polym. Sci., 1981, 38, 55.

8 A.G. Shostenko and V.E. Myshkin, Doklady Akademii Nauk SSSR, 1979, 246, 1429.

9 V.F. Gromov and P.M. Khomikovskii, Russ. Chem. Rev., 1979, 48, 1943.

10 M. Buback, Prog. PolymSci., 2002, 27, 191.

11 M. Buback and J. Schweer, Z. Phys. Chem. NF. 1989, 161, 153.

12 M. Buback, Macromol. Symp. 2009, 275-276, 90.

13 F. Suganuma, S. Machi, H. Mitsui, M. Hagiwara and T. Kagiya, J. Polym. Sci. Part A-1: Polym. Chem., 1968, 6, 2069.

14 S. Munari and S. Russo J. Polym. Sci., 1979, 4, 773.

15 V.F. Gromov and P.M. Khomikovskii, Russ. Chem. Rev., 1979, 48, 1040 .

16 C. Barner-Kowollik and G.T. Russell, Prog. Polym. Sci. 2009, 34, 1211.

17 J. Barth and M. Buback, Macromol. React. Eng. 2010, 4, 288.

18 O.F. Olaj and E. Scnoll-Bitai, Monatshefte für Chemie, 1999, 130, 731 .

19 S. Beuermann and N. García, N. Macromolecules, 2004, 37, 3018.

20 G. Henrichi-Olivé and S. Olivé, Z. Phys. Chem. NF, 1965, 47, 286.

21 G. Henrichi-Olivé and S. Olivé, Z. Phys. Chem. NF, 1966, 48, 35.

22 L.A. Smirnova, N.A. Kopylova and V.V. Izvolenskii, Eur. Polym. J., 1996, 32, 1213.

23 Identical solubilities were measured for toluene, THF, DEC thanks to the method described in our previous work. ${ }^{[6]}$ Then we assume that the ethylene solubility is mostly independent of the solvent.

24 A. Loupy, in Effets de milieu en synthèse organique: Des effets de solvants aux méthodes d'activation non classiques, 2 nd ed. (Ed : A. Loupy), Dunod, 1996, pp 1-40.

25 Assuming that AIBN dissociation being similar in all solvents, and that the molecular weight is only controlled by the transfer to solvent.
26 G.B. Galland, R.F. de Souza, R.S. Mauler and F.F. Nunes, Macromolecules, 1999, 32, 1620.

27 C. Reichardt, in Solvents and solvent effects in organic chemistry, 2nd ed.; (Ed: C. Reichardt), VCH:Weinhei, 1988, pp 121-205.

28 C. Reichardt, in Solvents and solvent effects in organic chemistry, 2nd ed.; (Ed: C. Reichardt), VCH:Weinhei, 1988, pp 5-41.

29 R. C. Reid, J. M. Prausnitz and B. E. Poling, in The properties of gases and liquids, (Ed: R. C. Reid, J. M. Prausnitz and B. E. Poling), McGraw-Hill Book Company: Singapore, 1988, pp 74-84.

30 To determine the exact structure of the activated state, theoretical calculations have to be done.

31 For details of the calculation see ESI.

32 M. J. Frisch, G. W. Trucks, H. B. Schlegel, G. E. Scuseria, M. A. Rob, J. R. Cheeseman, J. A. Montgomery Jr., T. Vreven, K. N. Kudin, J. C. Burant, J. M. Millam, S. S. Iyengar, J. Tomasi, V. Barone, B. Mennucci, M. Cossi, G. Scalmani, N. Rega, G. A. Petersson, H. Nakatsuji, M. Hada, M. Ehara, K. Toyota, R. Fukuda, J. Hasegawa, M. Ishida, T. Nakajima, Y. Honda, O. Kitao, H. Nakai, M. Klene, X. Li, J. E. Knox, H. P. Hratchian, J. B. Cross, V. Bakken, C. Adamo, J. Jaramillo, R. Gomperts, R. E. Stratmann, O. Yazyev, A. J. Austin, R. Cammi, C. Pomelli, J. W. Ochterski, P. Y. Ayala, K. Morokuma, G. A. Voth, P. Salvador, J. J. Dannenberg, V. G. Zakrzewski, S. Dapprich, A. D. Daniels, M. C. Strain, O. Farkas, D. K. Malick, A. D. Rabuck, K. Raghavachari, J. B. Foresman, J. V. Ortiz, Q. Cui, A. G. Baboul, S. Clifford, J. Cioslowski, B. B. Stefanov, G. Liu, A. Liashenko, P. Piskorz, I. Komaromi, R. L. Martin, D. J. Fox, T. Keith, M. A. Al-Laham, C. Y. Peng, A. Nanayakkara, M. Challacombe, P. M. W. Gill, B. Johnson, W. Chen, M. W. Wong, C. Gonzalez, and J. A. Pople, Gaussian 03 (Gaussian, Inc., Wallingford, CT, 2003). 
Electronic Supplementary Information

\section{Unusual Activation by Solvent of the Ethylene Free Radical}

\section{Polymerization}

Etienne Grau, Jean-Pierre Broyer, Christophe Boisson, Roger Spitz, Vincent Monteil* 
Details of calculation of the optimum of solvent properties thanks to the Arrhenius parameters.

Free radical polymerization kinetics law link monomer conversion to the global kinetic constant. Thanks to the set of experiments we now the Arrhenius parameters dependence to the solvent properties $(\mu / \varepsilon)^{2}$.

$$
\begin{aligned}
& \ln \frac{1}{1-x} \propto k_{t o t} \\
& \ln k_{t o t}=\ln A_{t o t}-\frac{E_{t o t}}{R T} \\
& X=(\mu /)^{2}>0 \\
& \ln A_{t o t}=a \frac{1}{X}+b \\
& E_{t o t}=c X+d
\end{aligned}
$$

Then we can calculate the optimum dependence with the temperature.

$$
\begin{aligned}
\frac{\partial \ln k_{t o t}}{\partial X} & =0 \\
\frac{\partial \ln k_{t o t}}{\partial X} & =\frac{\partial \ln A_{t o t}}{\partial X}-\frac{1}{R T} \frac{\partial E_{t o t}}{\partial X} \\
0 & =-a \frac{1}{X^{2}}-\frac{c}{R T} \\
X & =\sqrt{-\frac{a R T}{c}}
\end{aligned}
$$




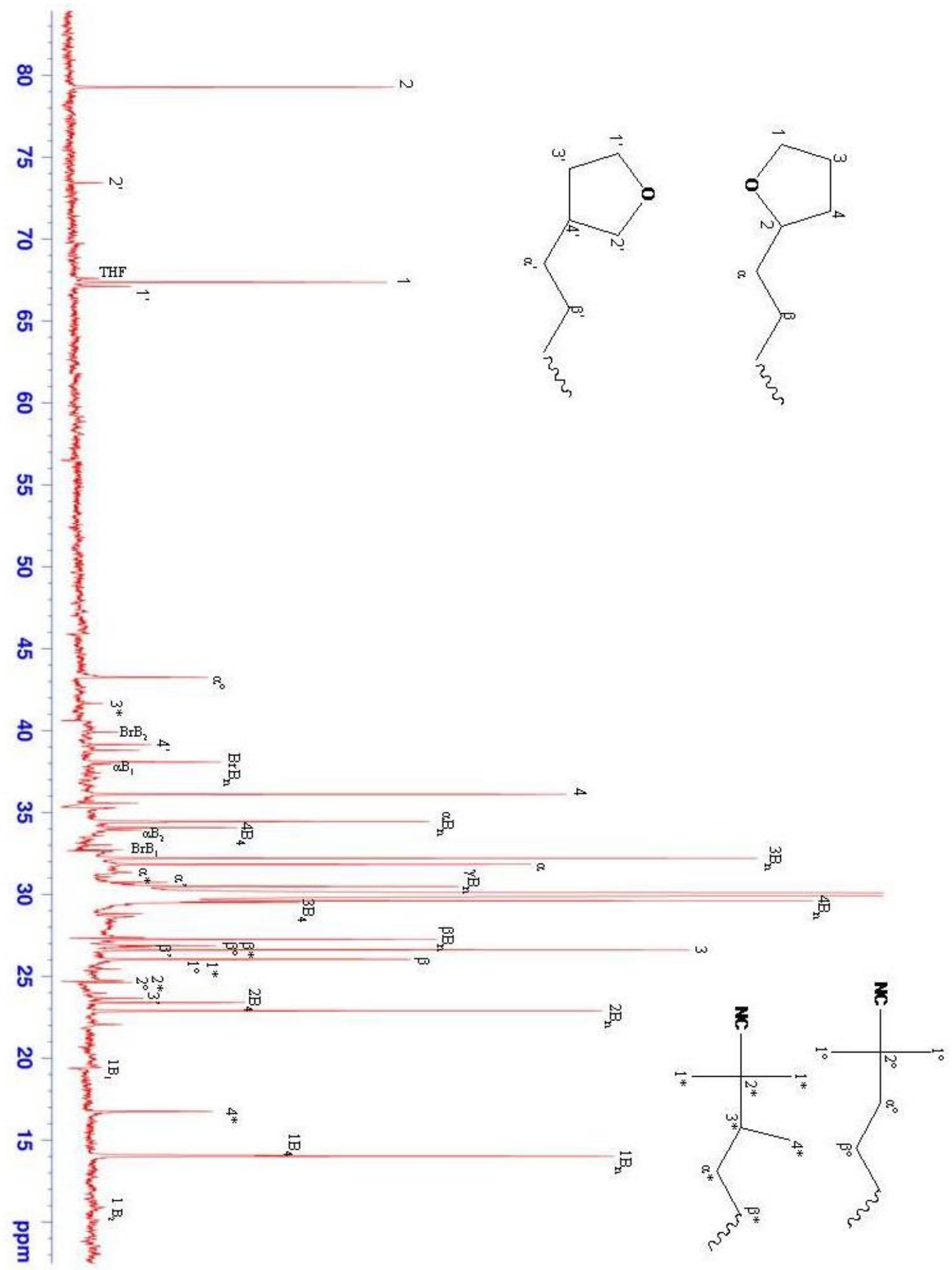

Figure S1: Typical ${ }^{13} \mathrm{C}$ NMR of polyethylene prepared in THF (notations from Galland et al for branching description ref 22 and ref 5 of the article) 


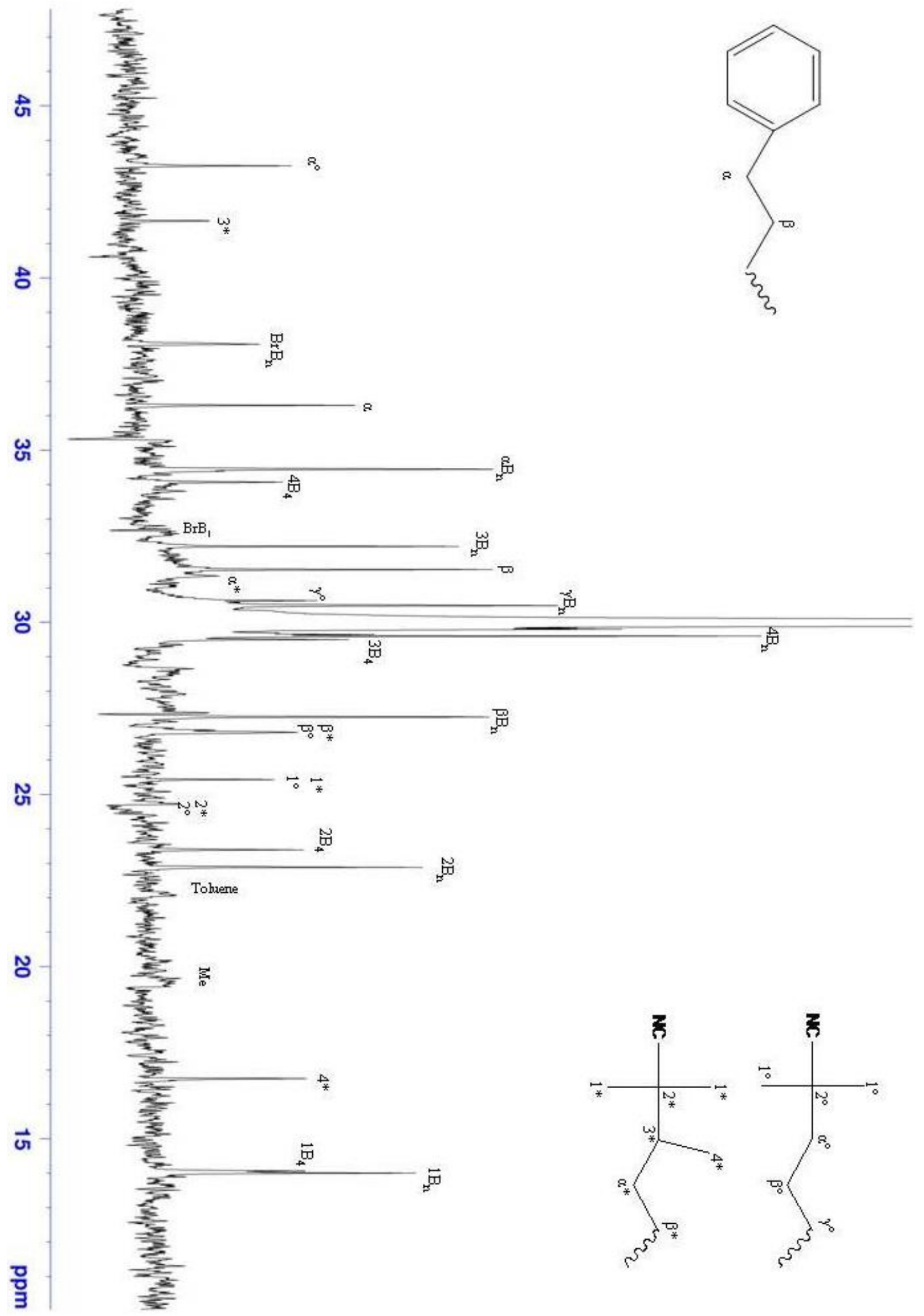

Figure S2: Typical ${ }^{13} \mathrm{C}$ NMR of polyethylene prepared in toluene (notation from Galland et al) 


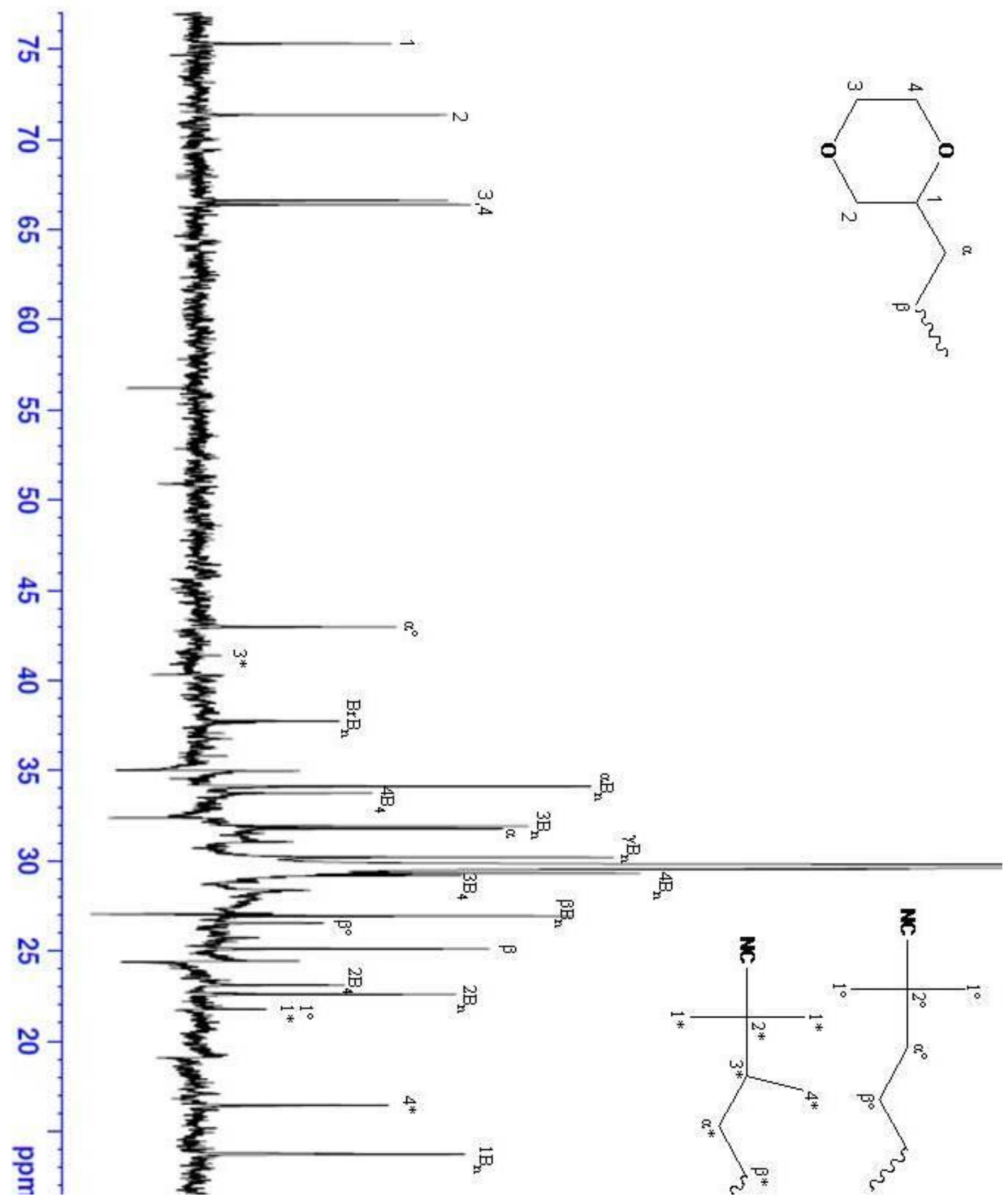

Figure S3: Typical ${ }^{13} \mathrm{C}$ NMR of polyethylene prepared in dioxane (notation from Galland et al) 


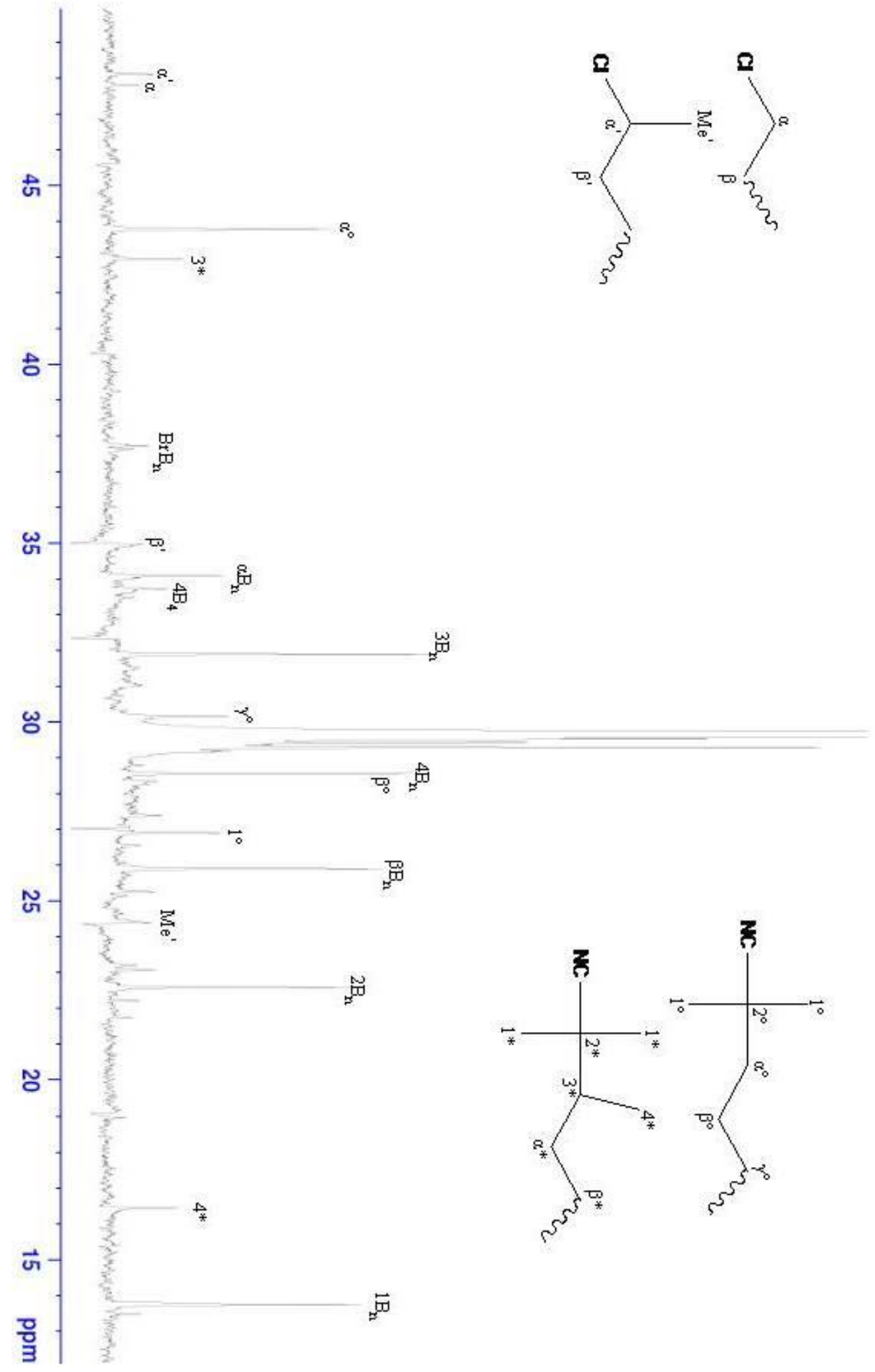

Figure S4: Typical ${ }^{13} \mathrm{C}$ NMR of polyethylene prepared in dichloromethane (notation from Galland et al) 
Table S1 : Solvent mixture composition effect on radical polymerization of ethylene ${ }^{\mathrm{a}}$

\begin{tabular}{|c|c|c|c|c|}
\hline Run & $\begin{array}{c}\text { Solvent } \\
\text { composition in } \\
\text { volume (\% } \\
\text { toluene / \% THF/ } \\
\% \text { DEC) }\end{array}$ & $\begin{array}{c}\text { Yield } \\
\text { (g) }\end{array}$ & $\operatorname{Mn}(\mathrm{g} / \mathrm{mol})$ & PDI \\
\hline $\begin{array}{c}21 \\
(=4)\end{array}$ & $100 / 0 / 0$ & 0.65 & 2340 & 1.9 \\
\hline 22 & $90 / 10 / 0$ & 0.75 & 1840 & 1.8 \\
\hline 23 & $70 / 30 / 0$ & 0.8 & 1260 & 2. \\
\hline 24 & $50 / 50 / 0$ & 1.1 & 1190 & 2.1 \\
\hline 25 & $30 / 70 / 0$ & 1.8 & 1170 & 2.1 \\
\hline 26 & $10 / 90 / 0$ & 3.1 & 1190 & 1.9 \\
\hline $\begin{array}{c}27 \\
(=21)\end{array}$ & $0 / 100 / 0$ & 3.9 & 1190 & 1.9 \\
\hline 28 & $0 / 90 / 10$ & 4 & 1270 & 1.8 \\
\hline 29 & $0 / 70 / 30$ & 3.8 & 1560 & 2.1 \\
\hline 30 & $0 / 50 / 50$ & 3.3 & 2490 & 1.7 \\
\hline 31 & $0 / 30 / 70$ & 2.4 & 2700 & 2.1 \\
\hline 32 & $0 / 10 / 90$ & 1.9 & 5360 & 2.4 \\
\hline $\begin{array}{c}33 \\
(=7)\end{array}$ & $0 / 0 / 100$ & 1.2 & 7150 & 2.5 \\
\hline 34 & $10 / 0 / 90$ & 1.8 & 6630 & 2.4 \\
\hline 35 & $30 / 0 / 70$ & 2.5 & 4650 & 2.1 \\
\hline 36 & $50 / 0 / 50$ & 4 & 3210 & 2.6 \\
\hline 37 & $70 / 0 / 30$ & 1.8 & 2640 & 2.1 \\
\hline 38 & $90 / 0 / 10$ & 0.7 & 2340 & 2.1 \\
\hline 39 & $40 / 40 / 20$ & 2 & 2650 & 1.6 \\
\hline 40 & $40 / 20 / 40$ & 4.1 & 5970 & 2 \\
\hline 41 & $20 / 40 / 40$ & 3.7 & 2010 & 2.2 \\
\hline
\end{tabular}

${ }^{\mathrm{a}}$ Reactions were carried at $70^{\circ} \mathrm{C}$ under 100 bar of ethylene pressure during $4 \mathrm{~h}$ with $50 \mathrm{mg}$ AIBN in $50 \mathrm{~mL}$ of solvent 
Table S2 : Temperature impact on radical polymerization of ethylene ${ }^{\mathrm{a}}$

\begin{tabular}{|c|c|c|c|c|}
\hline Run & Solvent & $\begin{array}{c}\text { Temperature } \\
\left({ }^{\circ} \mathrm{C}\right)\end{array}$ & $\begin{array}{c}\text { Ethylene } \\
\text { pressure } \\
\text { (bar) }\end{array}$ & $\begin{array}{c}\text { Yield (g) } \\
\text { [conversion \%] }\end{array}$ \\
\hline 42 & Toluene & 50 & 50 & $0.05[0.5 \%]$ \\
\hline 43 & Toluene & 70 & 50 & $0.25[2.7 \%]$ \\
\hline 44 & Toluene & 90 & 50 & $0.4[4.8 \%]$ \\
\hline 45 & Toluene & 50 & 100 & $0.15[0.4 \%]$ \\
\hline $46(=4)$ & Toluene & 70 & 100 & $0.7[2.6 \%]$ \\
\hline 47 & Toluene & 90 & 100 & $1.3[6.5 \%]$ \\
\hline 48 & Toluene & 50 & 150 & $0.15[0.4 \%]$ \\
\hline 49 & Toluene & 70 & 150 & $0.8[2 \%]$ \\
\hline 50 & Toluene & 90 & 150 & $1.7[5.2 \%]$ \\
\hline 51 & Toluene & 50 & 200 & $0.2[0.4 \%]$ \\
\hline 52 & Toluene & 70 & 200 & $1[2.1 \%]$ \\
\hline 53 & Toluene & 90 & 200 & $2[4.8 \%]$ \\
\hline 54 & Toluene & 50 & 250 & $0.25[0.4 \%]$ \\
\hline 55 & Toluene & 70 & 250 & $1.3[2.5 \%]$ \\
\hline 56 & Toluene & 90 & 250 & $2.5[5.3 \%]$ \\
\hline 57 & THF & 50 & 50 & $0.4[3.7 \%]$ \\
\hline 58 & THF & 70 & 50 & $2.9[31.2 \%]$ \\
\hline 59 & THF & 90 & 50 & $4.1[49.4 \%]$ \\
\hline 60 & THF & 50 & 100 & $0.6[1.8 \%]$ \\
\hline $\begin{array}{c}61 \\
(=21)\end{array}$ & THF & 70 & 100 & $3.9[15.7 \%]$ \\
\hline 62 & THF & 90 & 100 & $9[44.7 \%]$ \\
\hline 63 & THF & 50 & 150 & 0.8 [1.7\%] \\
\hline
\end{tabular}




\begin{tabular}{|c|c|c|c|c|}
\hline 64 & $\mathrm{THF}$ & 70 & 150 & $5.9[15 \%]$ \\
\hline 65 & $\mathrm{THF}$ & 90 & 150 & 11 [33.6\%] \\
\hline 66 & THF & 50 & 200 & $1[1.9 \%]$ \\
\hline 67 & $\mathrm{THF}$ & 70 & 200 & $6.5[13.8 \%]$ \\
\hline 68 & $\mathrm{THF}$ & 90 & 200 & $14.5[35 \%]$ \\
\hline 69 & $\mathrm{THF}$ & 50 & 250 & $1.2[2.1 \%]$ \\
\hline 70 & $\mathrm{THF}$ & 70 & 250 & $7.8[14.9 \%]$ \\
\hline 71 & $\mathrm{THF}$ & 90 & 250 & 17 [35.9\%] \\
\hline 72 & $\mathrm{DEC}$ & 50 & 50 & $0.1[0.9 \%]$ \\
\hline 73 & $\mathrm{DEC}$ & 70 & 50 & 0.7 [7.5\%] \\
\hline 74 & $\mathrm{DEC}$ & 90 & 50 & $2.5[30.1 \%]$ \\
\hline 75 & $\mathrm{DEC}$ & 50 & 100 & $0.3[0.9 \%]$ \\
\hline $76(=7)$ & $\mathrm{DEC}$ & 70 & 100 & $1.2[3.5 \%]$ \\
\hline 77 & $\mathrm{DEC}$ & 90 & 100 & $4.3[12.5 \%]$ \\
\hline 78 & $\mathrm{DEC}$ & 50 & 150 & $0.2[0.4 \%]$ \\
\hline 79 & $\mathrm{DEC}$ & 70 & 150 & $1.9[4.8 \%]$ \\
\hline 80 & $\mathrm{DEC}$ & 90 & 150 & 5 [15.3\%] \\
\hline 81 & $\mathrm{DEC}$ & 50 & 200 & $0.2[0.4 \%]$ \\
\hline 82 & $\mathrm{DEC}$ & 70 & 200 & $2.9[6.2 \%]$ \\
\hline 83 & $\mathrm{DEC}$ & 90 & 200 & $6.3[15.2 \%]$ \\
\hline 84 & $\mathrm{DEC}$ & 50 & 250 & $0.2[0.3 \%]$ \\
\hline 85 & $\mathrm{DEC}$ & 70 & 250 & $3.5[6.6 \%]$ \\
\hline 86 & $\mathrm{DEC}$ & 90 & 250 & $7.2[15.2 \%]$ \\
\hline
\end{tabular}

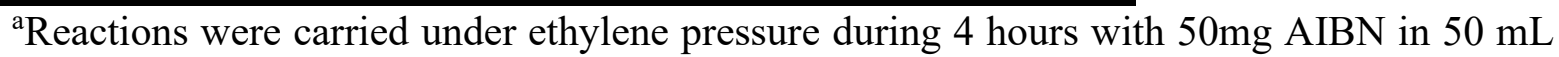
of solvent 
1-hexyl radical has been simulated using GAUSSIAN03 using restricted open shell B3LYP/6$311++\mathrm{G}$ basis.

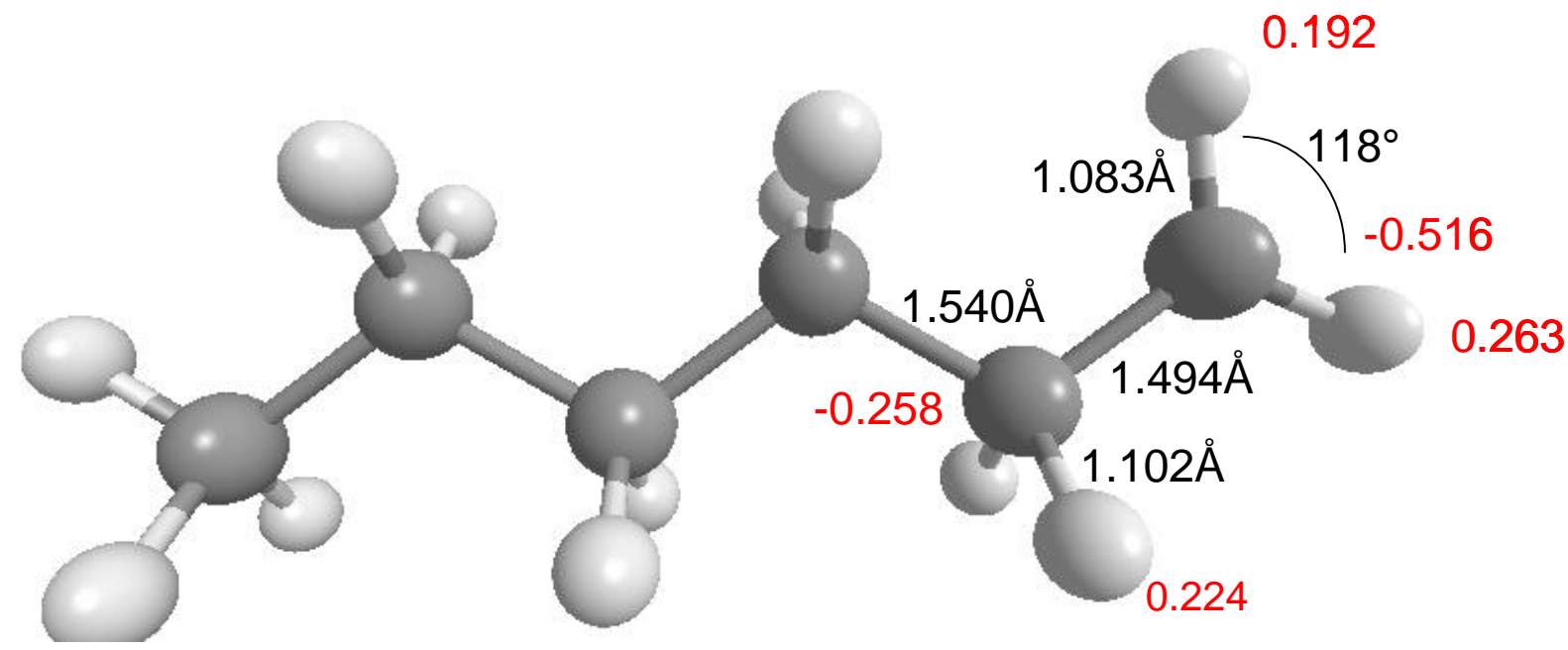

Figure S5: Relaxed 1-hexyl radical determined using GAUSSIAN03 calculation (in red are the partial Mulliken charge)

Table S3 : XYZ coordinates and mulliken charge of all atoms of 1-hexyl radical

\begin{tabular}{ccccc}
\hline & $\mathrm{X}(\AA)$ & $\mathrm{Y}(\AA)$ & $\mathrm{Z}(\AA)$ & Mulliken charge \\
\hline $\mathrm{C}$ & -3.068705 & -0.78129438 & -0.00968804 & -0.936163 \\
$\mathrm{C}$ & -1.899007 & 0.21412305 & -0.00092907 & -0.22222 \\
$\mathrm{C}$ & -0.520477 & -0.46837619 & -0.00412973 & -0.45143 \\
$\mathrm{C}$ & 0.6554958 & 0.52105771 & 0.00478151 & -0.500515 \\
$\mathrm{C}$ & 2.035075 & -0.16299197 & 0.00117502 & -0.258503 \\
$\mathrm{H}$ & 3.1874262 & 0.78814546 & 0.01004793 & -0.516226 \\
$\mathrm{H}$ & -4.03192 & -0.26585788 & -0.00728355 & 0.239686 \\
$\mathrm{H}$ & -3.038214 & -1.43268143 & 0.8680714 & 0.21495 \\
$\mathrm{H}$ & -3.035814 & -1.41996189 & -0.8966608 & 0.21494 \\
$\mathrm{H}$ & -1.976931 & 0.86169144 & 0.87977864 & 0.220248 \\
$\mathrm{H}$ & -1.974673 & 0.87445422 & -0.87230679 & 0.220244 \\
$\mathrm{H}$ & -0.442232 & -1.11642707 & -0.88584924 & 0.210398 \\
$\mathrm{H}$ & -0.44459 & -1.12941321 & 0.86810397 & 0.210358 \\
\hline & 0.5799197 & 1.16707995 & 0.88708638 & 0.225668 \\
\hline
\end{tabular}




\begin{tabular}{lllll}
\hline $\mathrm{H}$ & 0.5819664 & 1.18047349 & -0.86772897 & 0.225685 \\
$\mathrm{H}$ & 2.1035051 & -0.82799116 & -0.87428211 & 0.223605 \\
$\mathrm{H}$ & 2.1012486 & -0.8415595 & 0.86636991 & 0.223715 \\
$\mathrm{H}$ & 4.2081217 & 0.4266013 & 0.00732591 & 0.192124 \\
$\mathrm{H}$ & 3.030765 & 1.85960971 & 0.01982957 & 0.192124 \\
\hline
\end{tabular}

The punctual dipole momentum of the radical is calculated by $\mu_{\text {radical }}=\Sigma q_{i} r_{i}$ with an origine corresponding to the barycenter of the $\mathrm{C}_{2} \mathrm{H}_{2}{ }^{\bullet}$ unit. Therefore $\mu_{\text {radical }}=1.5009$ C.m. 
AIBN fragment radical has been simulated using GAUSSIAN03 using restricted open shell B3LYP/6-311++G basis.

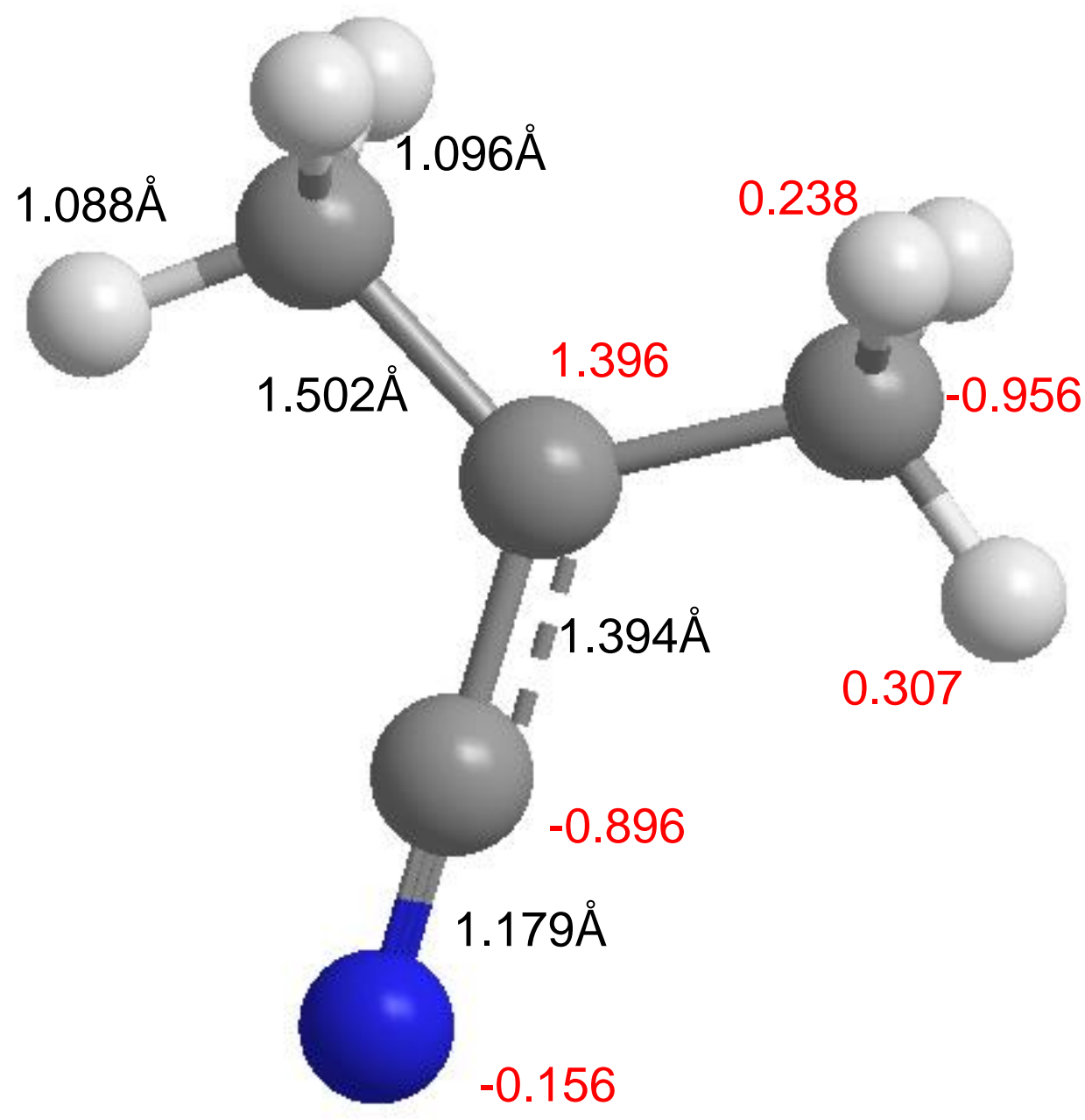

Figure S6: Relaxed AIBN fragment $\left(\left(\mathrm{CH}_{3}\right)_{2} \mathrm{C}^{\bullet} \mathrm{CN}\right)$ determined using GAUSSIAN03 calculation (in red are the partial Mulliken charge)

Table S4 : XYZ coordinates and Mulliken charge of all atoms of AIBN fragment

\begin{tabular}{ccccc}
\hline & $\mathrm{X}(\AA)$ & $\mathrm{Y}(\AA)$ & $\mathrm{Z}(\AA)$ & Mulliken charge \\
\hline $\mathrm{C}$ & -0.0122706683 & 0.2201925596 & -0.2163932989 & 1.395675 \\
$\mathrm{C}$ & 0.9974644499 & 1.3322570133 & -0.2254218486 & -0.955998 \\
$\mathrm{C}$ & -1.0755799762 & 0.1832120249 & -1.2767479919 & -0.955956 \\
$\mathrm{C}$ & 0.0395995858 & -0.7697845441 & 0.7632715439 & -0.895831 \\
$\mathrm{~N}$ & 0.0833215632 & -1.6072846018 & 1.5921380806 & -0.156196 \\
$\mathrm{H}$ & 1.7067482815 & 1.2509183719 & 0.5958362627 & 0.307336 \\
\hline
\end{tabular}




\begin{tabular}{lrrrr}
\hline $\mathrm{H}$ & 0.501442927 & 2.3070625122 & -0.154625786 & 0.238347 \\
$\mathrm{H}$ & 1.5615569264 & 1.3366018246 & -1.1653678806 & 0.238469 \\
$\mathrm{H}$ & -1.7482882897 & -0.6635400293 & -1.1557594958 & 0.307338 \\
$\mathrm{H}$ & -0.6263192804 & 0.1231975998 & -2.2748916962 & 0.238501 \\
$\mathrm{H}$ & -1.6736718546 & 1.1014896111 & -1.2584083956 & 0.238315 \\
\hline
\end{tabular}

The punctual dipole momentum of the radical is calculated by $\mu_{\text {radical }}=\Sigma q_{i} r_{i}$ with an origine corresponding to the barycenter of the AIBN fragment. Therefore $\mu_{\text {radical }}=1.605$ C.m. 